\title{
Mean platelet volume as a predictor of pulmonary hypertension in patients with stable COPD
}

This article was published in the following Dove Press journal:

International Journal of Chronic Obstructive Pulmonary Disease

\author{
Maha Fathy Mohamed' \\ Asmaa $\mathrm{Ali}^{2}$ \\ Ahmad Abbas (iD ${ }^{3}$ \\ Mohammad Shafiq Awad ${ }^{4}$ \\ Mohammad Gouda ${ }^{5}$ \\ Amany M Sediq ${ }^{6}$ \\ 'Chest Department, Faculty of Medicine, \\ Beni-Suef University, Beni-Suef, Egypt; \\ ${ }^{2}$ Abbaseya Chest Hospital, MOH, Cairo, \\ Egypt; ${ }^{3}$ Chest Department, Faculty of \\ Medicine, Zagazig University, Zagazig, \\ 445 I 9, Egypt; ${ }^{4}$ Cardiology Department, \\ Faculty of Medicine, Beni-Suef University, \\ Beni-Suef, Egypt; ${ }^{5}$ Cardiology \\ Department, Faculty of Medicine, Zagazig \\ University, Zagazig, Egypt; ${ }^{6} \mathrm{Clinical}$ and \\ Chemical Pathology Department, Faculty \\ of Medicine, Zagazig University, Zagazig, \\ Egypt
}

Background: Pulmonary hypertension $(\mathrm{PH})$ is one of the most common complications developed during the course of chronic obstructive pulmonary disease (COPD). Platelet activation plays an important role in its pathophysiology, and mean platelet volume (MPV) is considered a respectable index of platelet activation. The aim of this work is to assess the ability of MPV in predicting PH secondary to COPD as well as its severity.

Methods: A cross-sectional study was conducted on 228 stable COPD patients. CBC, echocardiography, and pulmonary function tests were performed.

Results: The prevalence of $\mathrm{PH}$ in stable COPD patients was high $(63 \%)$, and the majority of patients had a mild degree (33\%). There was no significant association between $\mathrm{PH}$ presence with different COPD grade, but, in very severe COPD, severe PH was significantly presented. MPV in COPD patients with $\mathrm{PH}$ was significantly higher than those without $(9.02 \pm 1.14$ vs $7.11 \pm 0.98, P<0.001)$. Moreover, a significant statistical rising of MPV with increased severity of $\mathrm{PH}$. Multivariate regression analysis of predictors of $\mathrm{PH}$ demonstrated that; MPV is a real predictor of $\mathrm{PH}$ in such patients. The likelihood probability of $\mathrm{PH}$ increased up to 7-times with increasing one unit of MPV; (OR=6.7). A cut-off value of MPV $>7.25$ had $96 \%$ sensitivity and $76 \%$ specificity in predicting $\mathrm{PH}$.

Conclusion: MPV was higher in COPD patients with $\mathrm{PH}$ and positively correlated with $\mathrm{PH}$ severity. If the data are to be confirmed, MPV may be taken into consideration in decisionmaking and management of COPD patients.

Keywords: COPD, mean platelet volume, pulmonary hypertension

\section{Introduction}

Chronic obstructive pulmonary disease (COPD) is a progressive and irreversible airway inflammation that leads to persistence airflow obstruction. It is also associated with many secondary consequences depending on the severity of the disease and the frequency of the inflammatory process. ${ }^{1,2}$

Pulmonary hypertension $(\mathrm{PH})$ can be defined, regardless of its etiological cause, as chronic persistent elevation of pulmonary artery pressure and pulmonary vascular resistance, which subsequently leads to right side heart failure. ${ }^{3}$ The WHO classified $\mathrm{PH}$ into four groups, while the PH secondary to COPD placed in group (3). ${ }^{4}$

It was discussed in 2018, during the 6th World Symposium on PH, to revise the hemodynamic definition and lower the threshold of mean pulmonary artery pressure (mPAP) in diagnosis of $\mathrm{PH}$ from : $25 \mathrm{mmHg}$ to $>20 \mathrm{mmHg}$, but this new definition is still premature. $^{5-7}$
Correspondence: Ahmad Abbas

Chest Department, Faculty of Medicine,

Zagazig University, Zagazig 44519, Egypt

Tel +20 II 55355369

Email amabbaas@zu.edu.eg 
The prevalence of $\mathrm{PH}$ in stable COPD is widely ranged (20-91\%) depending on many prospective views, such as PH definition, COPD severity grades, and the methods by which the pulmonary pressure is measured. ${ }^{8,9}$

COPD as a chronic systemic disease has been associated with low grade inflammatory disorder, which is demonstrated by an increase of inflammatory cytokines, blood leucocytes, C-reactive proteins, and many other inflammatory markers. ${ }^{10,11}$ Besides that chronic inflammatory state, pulmonary thrombosis was reported in $25 \%$ of COPD patients, 12 which may be due to platelets dysfunction and clotting system activation. ${ }^{13,14}$

Whatever the cause of platelet activation (either due to systemic inflammation, oxidative stress condition, or hypoxemia), ${ }^{15}$ the cascade of platelet aggregation has begun, leading to release of its chemical mediators and producing endothelial injury. ${ }^{13-16}$ The reactive platelet cells contain alpha and delta dens granules, the alpha granules stored a large amount of platelets growth factors (PGF), vasoactive substance as thromboxan A2 (TX A2), and many cytokines, such as interleukin (IL1 and 6), while delta granules stored a large amount of serotonin. ${ }^{17-20}$ The injured endothelium acts as a thrombogenic focus, ${ }^{21}$ which subsequently attracts more and more platelets and starts to release plenty of vasoactive substance, causing pulmonary vasoconstriction, proliferation of smooth muscle cells, and pulmonary remodeling. ${ }^{22}$

So, the platelets were involved in PH pathophysiology by different mechanisms of action; (1) thrombosis formation due to pulmonary vascular endothelial dysfunction, (2) inflammatory cytokines release, especially IL6, and (3) serotonin production, which was responsible for neutrophils aggregation producing various cycles of the inflammatory process. ${ }^{22}$
Mean platelet volume is one of the platelet indices which reflect its activity; it is a simple and easy way to predict platelets dysfunction, either by excess production and small size formation or large size with insufficient production. ${ }^{23-25}$

To our knowledge, there is no evidence in using MPV; a simple inflammatory marker, in predicting secondary $\mathrm{PH}$ in stable COPD patients, so the objectives of the current study were to try to answer that lack of information.

\section{Methods}

\section{Study design and population}

A multicenter cross-sectional study was carried out at BaniSwaif University Hospitals, Zagazig University Hospitals, and Abbassia Chest Hospital Outpatient Clinics from March 2017 to the end of May 2018, and included stable COPD patients. The research was approved by Bani-Swaif and Zagazig University Ethical Committees. The enrolled cases were diagnosed as regarding GOLD criteria, then classified accordingly Stable COPD was diagnosed clinically when the patient symptoms resembled the pre-exacerbation state and there was no need for hospital admission ${ }^{26}$

\section{Exclusion criteria}

The number of patients fulfilling the eligible criteria of the study reached $300 ; 72$ patients were excluded, as shown in Figure 1.

\section{Pulmonary function tests}

Spirometric pulmonary functions were done using the Spirometry system (Master screen 2001, version 4.5, Erich Jaeger GMBH, Germany) in triple readings records, and the highest value was selected.

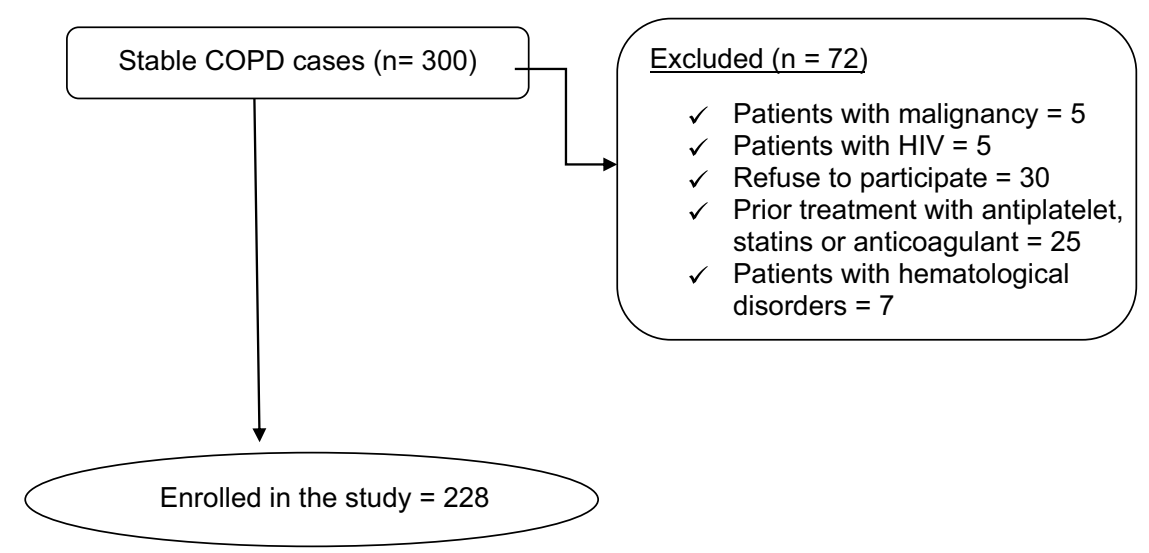

Figure I Flow chart of the studied patients. 


\section{Echocardiography}

All enrolled patients were subjected to trans-thoracic echocardiography using Ultrasound system (Vivid I, GE Healthcare, Little Chalfont, UK), with a $2.5 \mathrm{MHz}$ transducer. The simplified Bernoulli equation (4*TRV2) was used to calculate the pressure gradient over the tricuspid valve, and finally summated with right aerial pressure (RAP) to calculate the Pulmonary Artery Systolic Pressure (PASP), which is equal to Right Ventricular Systolic Pressure (RVSP). The patients seemed to have PH if RVSP $>30 \mathrm{mmHg}$. The patients seemed to have PH if PASP $>30 \mathrm{mmHg}$, and were classified into mild (30-50 $\mathrm{mmHg})$, moderate $(50-70 \mathrm{mmHg})$, and severe $\left(>70 \mathrm{mmHg}\right.$ ) degrees. ${ }^{27}$

\section{Biochemical measurement}

Including routine $\mathrm{CBC}$; TLC, PLT, $\mathrm{HB}$, and $\mathrm{RBC}$ with special consideration to MPV.

\section{Statistical methods}

The statistical analysis was done using Minitab 17.1.0.0 for windows (Minitab Inc., 2013, Pennsylvania, USA). Continuous date were presented as mean and SD, and categorical data as number and percent. The normality of data were examined using Shapilo Wilk test. Comparison between two continuous groups was done using independent Student's $t$-test and more than two groups with one-way ANOVA test. The two categorical groups or more were statistically analyzed using chi-square test. Pearson correlation coefficient test was used to examine the correlation between MPV and PASP in different COPD groups. Logistic regression analysis test with step wise elimination was used to predict the factors associated with $\mathrm{PH}$, also the simple linear regression equation was estimated to predict PASP from MPV. The accuracy of MPV was assessed with receiver operating curve analysis, assuming that the area under the ROC curve of 0.9 for this study was significant with a margin of type I error 0.05 and type II error 0.1 , the sample size calculated with a minimum total number of 70 and a minimum number of cases with PH of 35 using SigmaPlot software 12.5.0.38 for windows (SigmaPlot, Systat Software Inc. UK, 2011). All tests were two sided, $P<0.05$ was considered significant.

\section{Results}

The demographic and clinical criteria of the studied patients are summarized in Table 1. Depending on FEV1\%, the studied patients were classified according to the degree of airway obstruction into moderate (88 patients, 39\%), severe (75
Table I Characteristics of the studied patients $(n=228)$.

\begin{tabular}{|l|l|l|}
\hline Variable & mean/n & SD/\% \\
\hline Age (mean, SD) & 63.30 & 9.22 \\
\hline Smoking status (n, \%) & & \\
Smoker & 105.00 & 46.05 \\
Ex-smoker & 123.00 & 53.95 \\
\hline Smoking index (mean, SD) & 53.40 & 46.49 \\
\hline Co-morbidity (n, \%) & 21.00 & 9.21 \\
DM & 9.00 & 3.95 \\
HTN & 16.00 & 7.02 \\
\hline TLC (mean, SD) & 7.06 & 3.09 \\
RBCs (mean, SD) & 4.75 & 0.78 \\
HB (mean, SD) & 12.89 & 1.57 \\
PLT count (mean, SD) & 257.67 & 77.02 \\
MPV (mean, SD) & 8.33 & 1.42 \\
Arterial O ${ }_{2}$ Saturation (mean, SD) & 93.64 & 2.65 \\
PASP (mean, SD) & 43.24 & 17.61 \\
\hline
\end{tabular}

Abbreviations: SD, standard deviation; $n$, number; DM, diabetes mellitus; HTN, hypertension; TLC, total leucocytes count (cell/ $/ \mathrm{L})^{3} ; \mathrm{RBCs}$, red blood cell count $(\text { cell } / \mu \mathrm{L})^{3} ; \mathrm{HB}$, hemoglobin $(\mathrm{mg} / \mathrm{dL}) ; \mathrm{PLT}$, platelets count (cell/ $\left./ \mathrm{LL}\right)^{3}$; MPV, mean platelet volume (fL); PASP, pulmonary artery systolic pressure $(\mathrm{mmHg})$.

patients, 33\%), and very severe (65 patients, $28 \%$ ) groups according to GOLD classification protocol.

The prevalence of $\mathrm{PH}$ in stable COPD patients was high (63\%), and the majority of patients with $\mathrm{PH}$ were in the mild degree $(33 \%)$ group, while both moderate and severe $\mathrm{PH}$ represented $15 \%$ each. There were no significant associations of $\mathrm{PH}$ presence with different degrees of COPD $(P=0.35$ ) (Figure 2), but, in the very severe COPD groups, a severe degree of $\mathrm{PH}$ was significantly presented $(P=0.002)$ (Figure 3).

Considering the correlation between COPD stage with PASP and MPV, a significant statistical elevation of both PASP ( $\mathrm{mmHg}$ ) and MPV (fL) was reported in very severe COPD group ( $P=0.02$ and $<0.001$, respectively) (Table 2 ), Moreover, the correlation between MPV and PASP was significantly positive, whatever the degree of COPD severity $(\mathrm{r}=0.79 ; P<0.001)$ (Figure 4$)$.

MPV in COPD patients with PH was significantly higher than those without $(9.02 \pm 1.14$ vs $7.11 \pm 0.98$, $P<0.001)$. Moreover, a significant statistical rising of MPV with increased severity of PH, $P<0.001$ (Table 3).

Multivariate regression analysis of predictors of $\mathrm{PH}$ demonstrated that; MPV and PLT cell counts were significantly capable in predicting $\mathrm{PH}$. The likelihood probability of PH increased up to 7 times with increasing one unit of MPV $(\mathrm{OR}=6.7, P<0.001)($ Table 4$)$. 


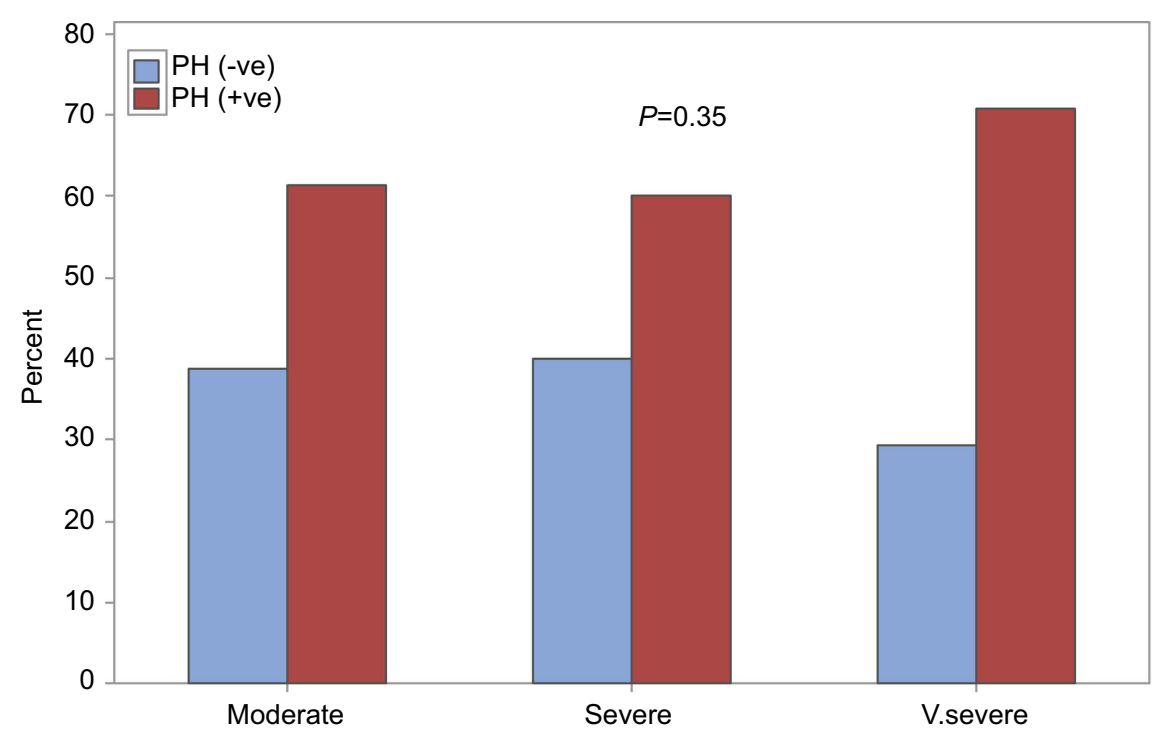

Figure $2 \mathrm{PH}$ status in different COPD groups.

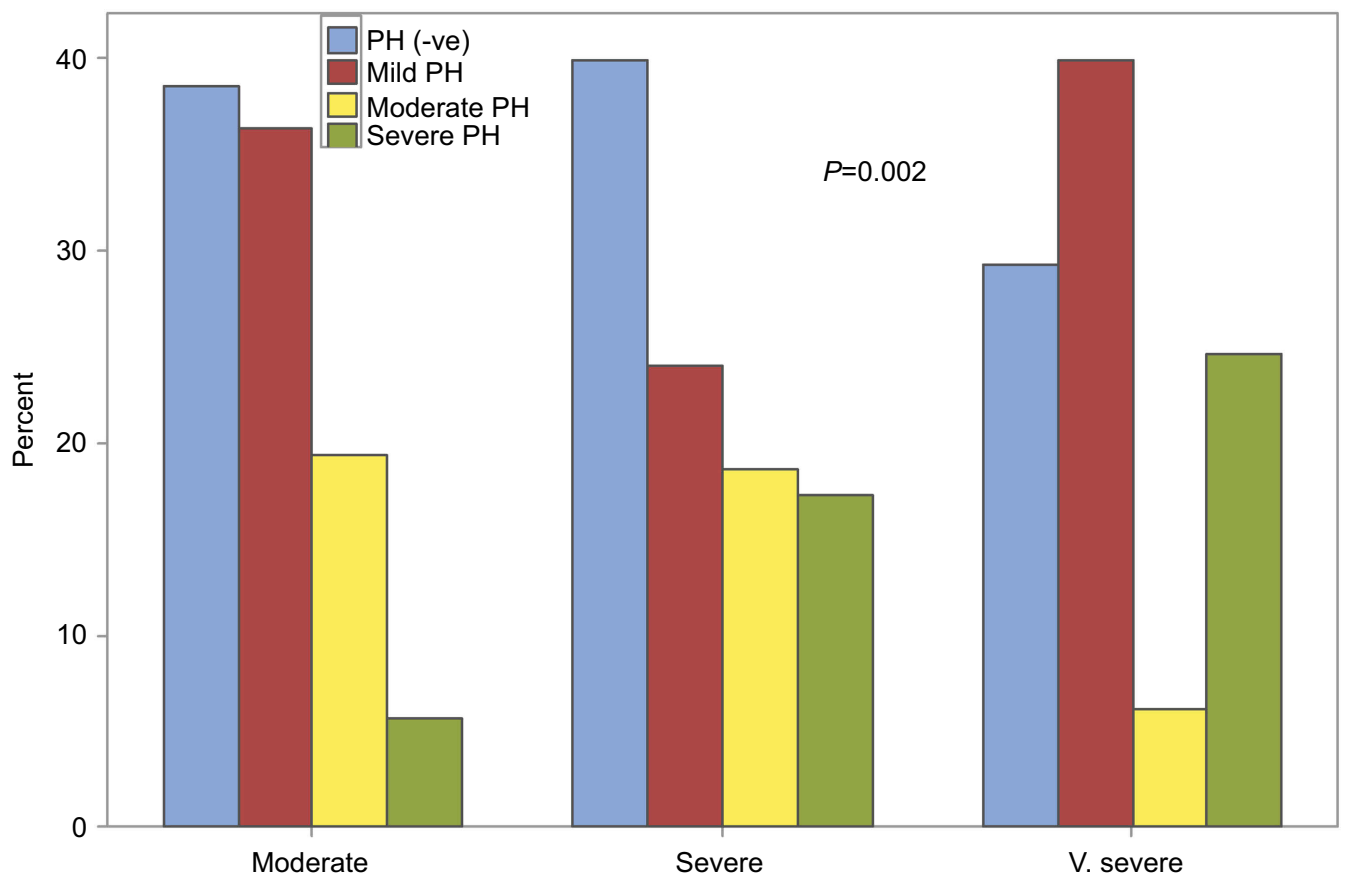

Figure 3 Severity degree of $\mathrm{PH}$ in different COPD groups.

The validity of MPV in predicting PH was excellent and significant; the AUC was $0.9(P<0.001)$ (Figure 5A). A cut-off value of MPV $>7.25$ had $96 \%$ sensitivity and $76 \%$ specificity in predicting $\mathrm{PH}$. In predicting severe $\mathrm{PH}$, the AUC was 0.95 $(P<0.001)$ (Figure 5B). A cut-off value of MPV $>9.75$ had $94 \%$ sensitivity and $89 \%$ specificity in predicting severe $\mathrm{PH}$.

There was no statistically significant difference in mean MPV or mPAP with increased number of exacerbation per year, as shown in Figures 6 and 7.
The linear regression analysis of MPV established that it hada statistically significant predictive ability for PASP reading, $P<0.001$, and it accounted for $63.7 \%$ of the explained variability in PASP. The regression equation was: $\mathrm{PASP}=(-38.93+9.869 \mathrm{MPV})$ (Figure 8$)$.

\section{Discussion}

Due to the higher prevalence of COPD, PH associated with COPD was one of the most frequent causes of $\mathrm{PH} 2$ 
Table $2 \mathrm{PH}$ and MPV in correlation with different COPD groups

\begin{tabular}{|c|c|c|c|c|c|c|c|}
\hline \multirow{3}{*}{$\begin{array}{l}\text { Variable } \\
\text { PH (n, \%) }\end{array}$} & \multicolumn{6}{|c|}{ COPD grades } & \multirow{3}{*}{$\begin{array}{l}\boldsymbol{P} \\
0.35^{\#}\end{array}$} \\
\hline & \multicolumn{2}{|c|}{ Moderate $(n=88)$} & \multicolumn{2}{|c|}{ Severe $(n=75)$} & \multicolumn{2}{|c|}{ Very severe $(n=65)$} & \\
\hline & 54 & 61.36 & 45 & 60 & 46 & 70.77 & \\
\hline \multicolumn{8}{|l|}{$\mathrm{PH}$ grades (n, \%) } \\
\hline Mild & 32 & 36.36 & 18 & 24 & 26 & 40 & $0.002^{\#}$ \\
\hline Moderate & 17 & 19.32 & 14 & 18.67 & 4 & 6.15 & \\
\hline Severe & 5 & 5.68 & 13 & 17.33 & 16 & 24.62 & \\
\hline MPV (mean, SD) & 8.01 & 1.07 & 8.18 & 1.7 & 8.93 & 1.32 & $<0.001^{\$}$ \\
\hline PASP (mean, SD) & 39.48 & 15.38 & 44.2 & 18.8 & 47.23 & 18.24 & $0.02^{\$}$ \\
\hline
\end{tabular}

Notes: ${ }^{\#}$ Chi-square test, ${ }^{\$}$ One way ANOVA test, $P<0.05$ is considered significant.

Abbreviations: COPD, chronic obstructive pulmonary disease; MPV, mean platelet volume (fL); PASP, pulmonary artery systolic pressure (mmHg); PH, pulmonary hypertension.

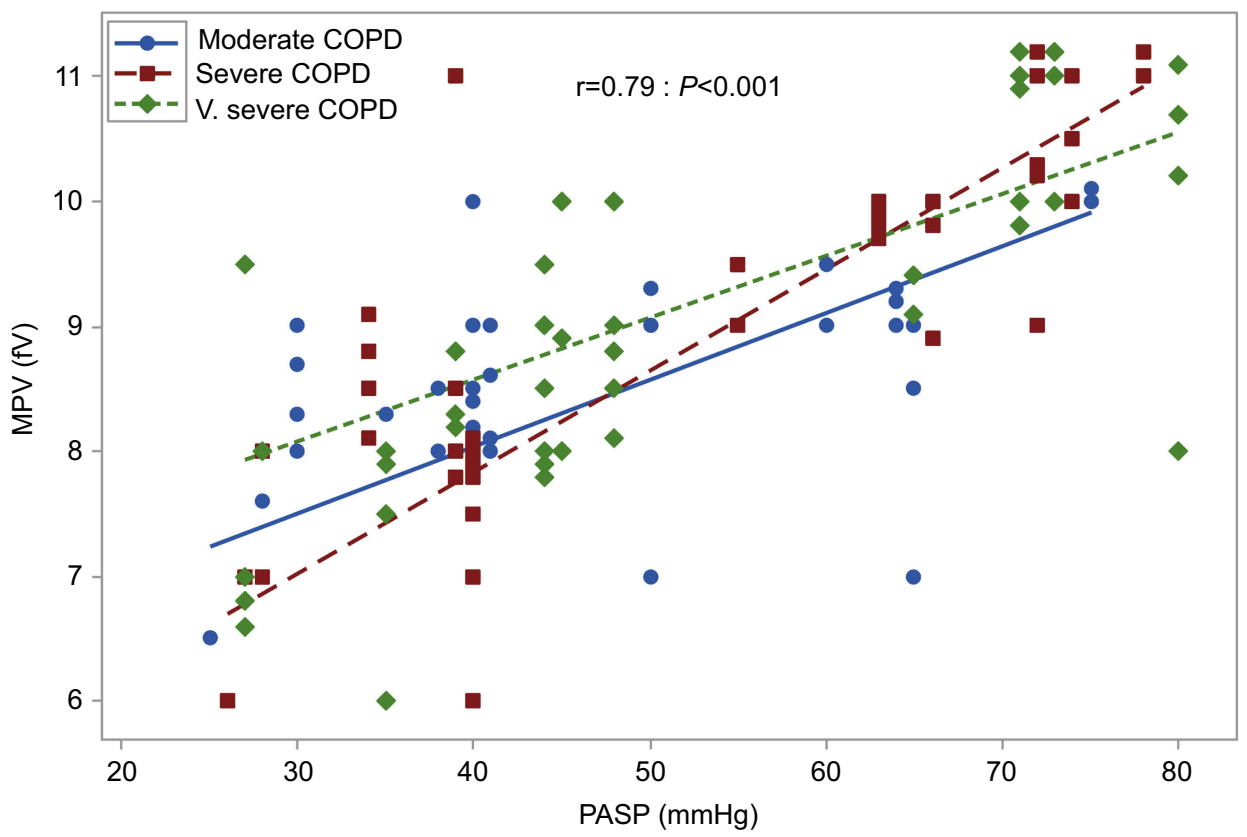

Figure 4 Correlation between MPV and PASP.

Table 3 MPV in patients with $\mathrm{PH}$

\begin{tabular}{|l|l|l|l|}
\hline \multirow{2}{*}{ PH } & \multicolumn{2}{|l|}{ MPV } & \multirow{2}{*}{} \\
\cline { 2 - 3 } & Mean & SD & \\
\hline No $(n=83)$ & 7.11 & 0.98 & $<0.001^{\wedge}$ \\
Yes $(n=145)$ & 9.02 & 1.14 & \\
\hline PH grades & & & \\
Mild (n=76) & 8.32 & 0.77 & $<0.001^{\$}$ \\
Moderate (n=35) & 9.14 & 0.66 & \\
Severe $(n=34)$ & 10.49 & 0.71 & \\
\hline
\end{tabular}

Notes: ^Independent $t$-test, ${ }^{\$}$ One way ANOVA test, $P<0.05$ considered significant. Abbreviations: MPV, mean platelet volume; $\mathrm{PH}$, pulmonary hypertension.
Table 4 Predictors of $\mathrm{PH}$ in COPD patients using adjusted logistic regression models

\begin{tabular}{|l|l|l|l|}
\hline Variables & OR & $\mathbf{9 5 \%} \mathbf{C I}$ & $\boldsymbol{P}$ \\
\hline PLT & 1.02 & $(1.0077-1.0300)$ & 0.001 \\
MPV & 6.70 & $(4.1205-10.8903)$ & $<0.001$ \\
TLC & 0.98 & $(0.7376-1.2944)$ & 0.87 \\
FEVI & 0.99 & $(0.9673-1.0122)$ & 0.37 \\
Exacerbation frequency & 0.59 & $(0.3454-1.0122)$ & 0.051 \\
\hline
\end{tabular}

Notes: Pearson; $X^{2}=210.5, P=0.9$, the model was adjusted for all variables using stepwise elimination.

Abbreviations: COPD, chronic obstructive pulmonary disease; FEVI, forced expiratory volume in the first second; MPV, mean platelet volume (fL); $\mathrm{PH}$, pulmonary hypertension; PLT, platelets count; TLC, total leucocytes count. 
A

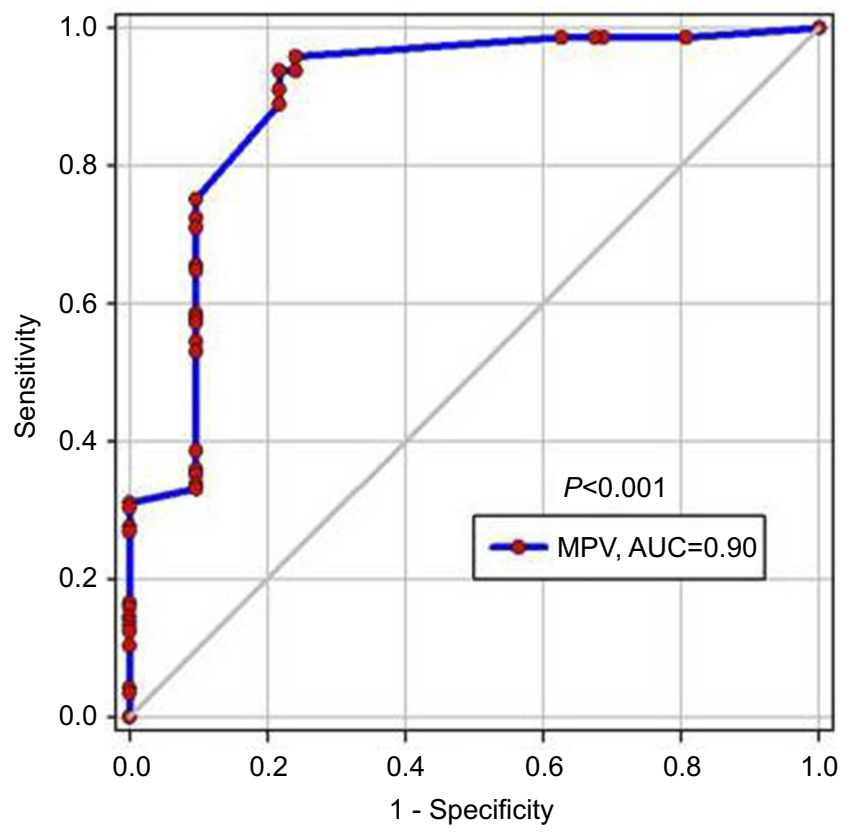

B

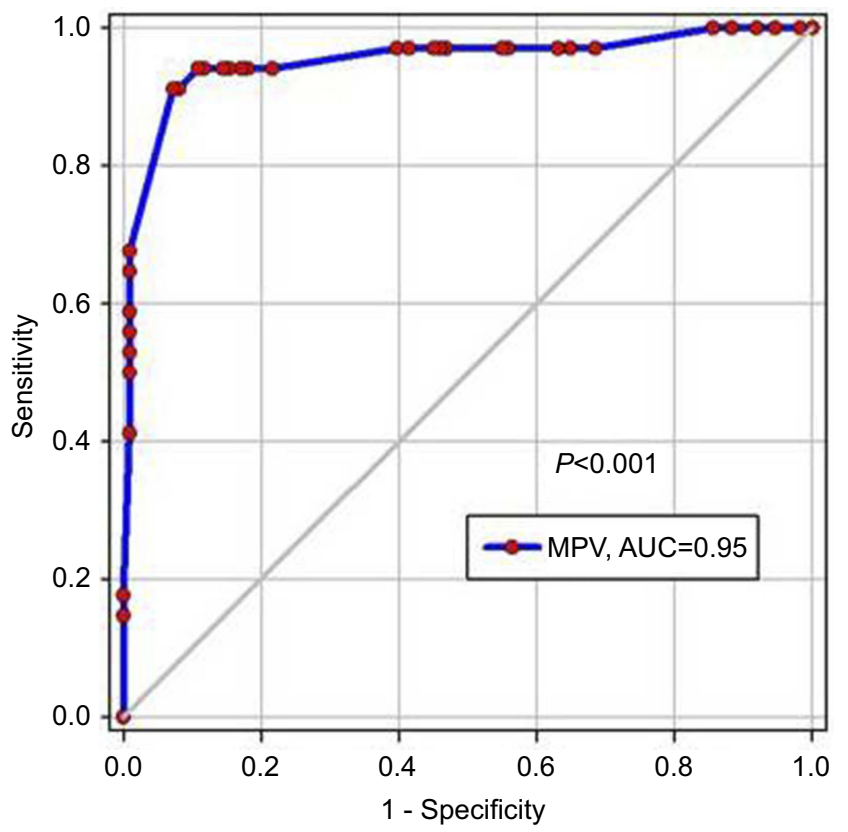

Figure 5 ROC curve analysis of MPV. (A) In predicting PH. (B) In predicting severe $\mathrm{PH}$.

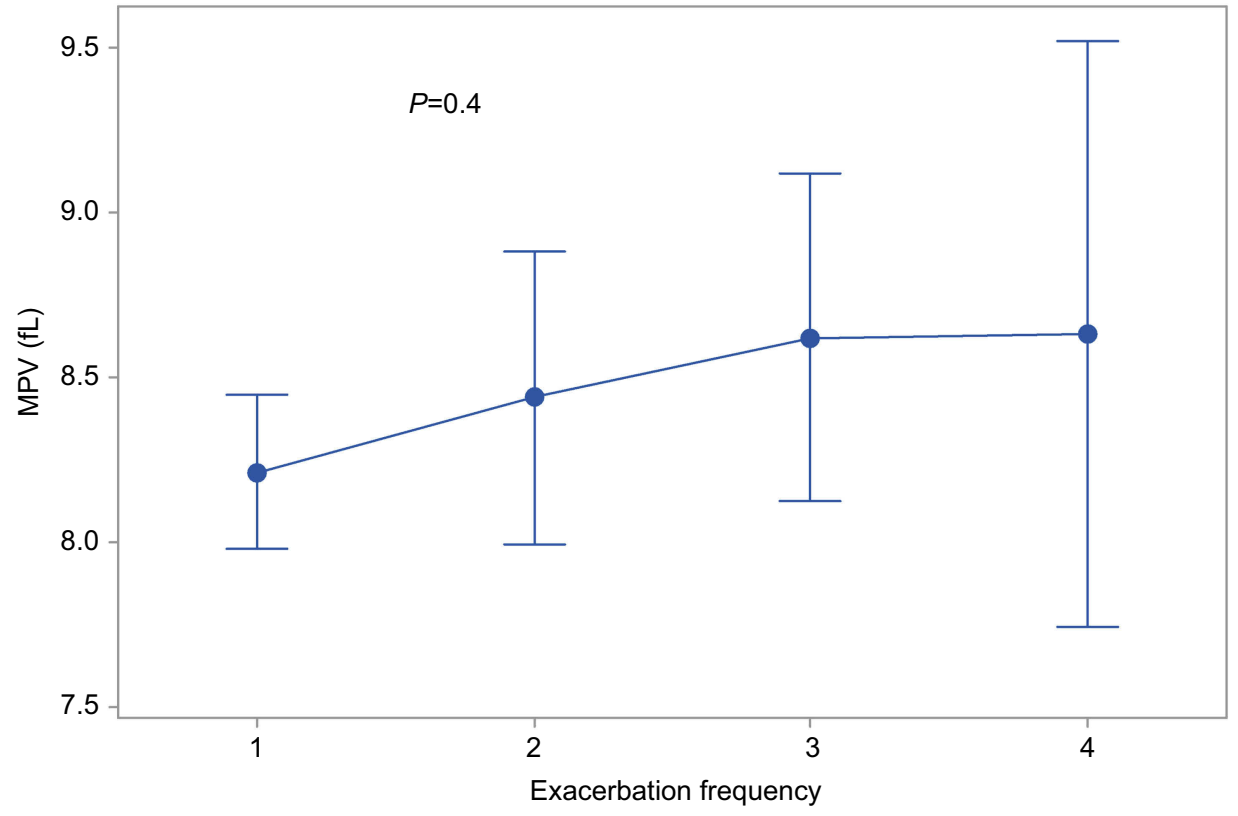

Figure 6 Correlation between exacerbation frequency and MPV.

The 5-year survival rate was only $36 \%$ in COPD patients with initial mPAP $>25 \mathrm{mmHg}$, compared to $62 \%$ in those with initial $\mathrm{mPAP} \leq 25 \mathrm{mmHg}^{28}$

The current study reported a $63 \%$ prevalence of $\mathrm{PH}$ in the studied COPD patients, mild PH represented 33\%, while moderate and severe $\mathrm{PH}$ represented $15 \%$ each. This is in agreement with Maula et $\mathrm{al}^{29}$ and $\mathrm{Ali}^{30}{ }^{30}$ in their studies; the prevalence of $\mathrm{PH}$ was $65.4 \%$ and $60 \%$, respectively, which closely resembled the international studies by Chaouat et $\mathrm{al}^{31}$ and Chatila et al. ${ }^{32}$ Also, Gajanan and Pophale ${ }^{33}$ agreed that the frequencies of mild, moderate, and severe $\mathrm{PH}$ were $23 \%, 18 \%$, and $12 \%$, respectively. On the contrary, Naeije $\mathrm{e}^{34}$ recorded a lower prevalence, of less than $10 \%$. 


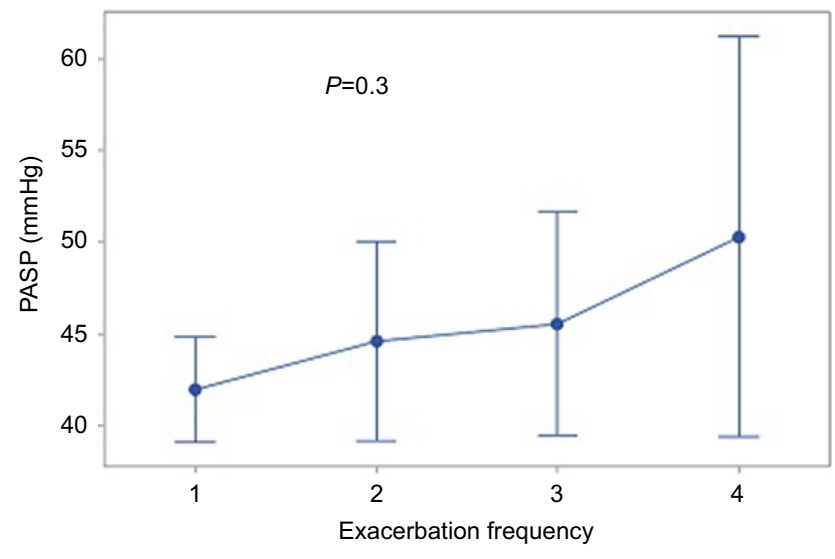

Figure 7 Correlation between exacerbation frequency and PASP.

The prevalence of PH in COPD was varied from one study to another; from $18 \%{ }^{35}$ to up to $91 \%,{ }^{36}$ but most studies were based on pulmonary hemodynamic assessments conducted in those referred for surgical procedures; a prevalence cannot be generalized to the whole COPD population $^{37}$

The current study examined the MPV and its correlation with COPD severity grades, with furthermore correlation with $\mathrm{PH}$ presence, it was established that the MPV was significantly increased by increasing the severity of COPD $(P<0.001)$ (Table 2), and also had a significant statistical elevation in patients with $\mathrm{PH}$ compared to those without. In comparing the MPV level in each PH degree, a significant statistical elevation was present in the severe PH group, $P<0.001$ (Table 3). That correlation between PASP was independently present, whatever the degree of COPD $(\mathrm{r}=0.79 ; P<0.001)$ (Figure 4).

Consistent with a recent report, ${ }^{30}$ a significant positive correlation between MPV and increased severity of PAH was found. Another study ${ }^{38}$ found that the MPV was increased with more advancement of COPD stage, but with an insignificant statistical difference, this might be due to the small sample size and lower number of patients at stage IV included in that study. Other contrasting reports ${ }^{16,38}$ stated that MPV was not correlated with pulmonary function results nor COPD severity stage.

The platelet dysfunction in patients with COPD was summarized in many studies; ${ }^{12-14,39-42}$ platelets activation, increased aggregation, and platelet volume in pulmonary vessels which could possibly lead to PH and pulmonary thrombosis. Hence, Alessandri et al ${ }^{12}$ found pulmonary thrombosis in approximately $25 \%$ of patients with COPD on autopsy. Also, Bansal et $\mathrm{al}^{21}$ added a significantly higher MPV in patients with COPD, which could possibly contribute to increased pulmonary thrombosis and hypertension.

In line with the current work, the relationship between MPV and PH had been shown in previous studies. Can et $\mathrm{al}^{43}$ reported that MPV levels were higher in patients with $\mathrm{PH}$ than in the control groups $(9.1$ vs $8.2, P<0.001)$ and concluded that platelet activation may directly impact

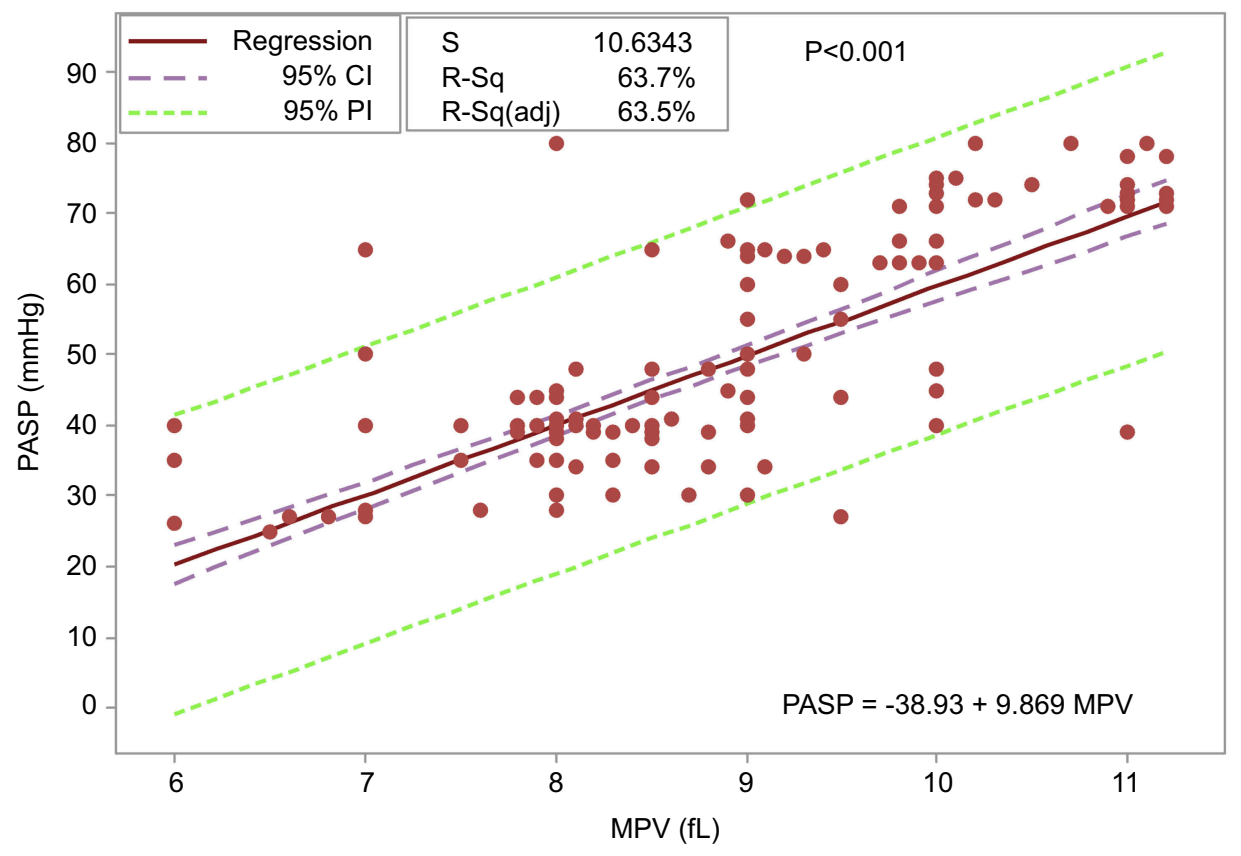

Figure 8 PASP prediction equation using MPV. 
the pathogenesis of $\mathrm{PH}$. Other studies have shown that patients with COPD had increased MPV values, especially in those with known PH. ${ }^{12,39}$ Also, Varol et al ${ }^{44}$ investigated MPV levels in patients with PH, and they found that MPV levels were higher in patients than in the control groups (8.68 vs $8.02, P=0.006)$ and concluded that increased MPV was present in patients with $\mathrm{PH}$.

Güvenc et $\mathrm{a}^{45}$ agreed, in their study (Comparison of mean platelet volume values among different causes of pulmonary hypertension) that MPV values in the $\mathrm{PH}$ group were increased compared to healthy controls, but, in his study, sub-group analysis revealed that MPV levels in the COPD group were higher compared to normal controls; this finding did not reach statistical significance. This difference may be due to the small number of COPD patients included in his analysis. On the other hand, Arslan et $\mathrm{al},{ }^{46}$ who evaluated MPV among children with congenital heart disease (CHD) in left-to-right shunt patients with and without PAH, a significant decrease in MPV was noted in patients with $\mathrm{PH}$ than those without. This may be explained by a different mechanism of $\mathrm{PH}$ among patients with congenital heart disease than those with thrombo-embolic or hypoxic PH30

During COPD exacerbation, the baseline inflammatory state becomes worse, and increased pro-inflammatory cytokines such as CRP,TNF- $\alpha$ and IL- 6 may be involved in platelet activation. ${ }^{47}$

Also, COPD exacerbation has a cumulative effect on FEV1. Patients who experienced up to one moderate-tosevere exacerbation yearly had a $37 \%$ faster reduction in lung function than those without exacerbation. ${ }^{48}$ In the present study; a trend of increase MPV with more advancement of airway obstruction was reported (Table 2).

The link between exacerbation frequency (as a possible cause of chronic platelet activation) with either mean platelet volume or PASP was assessed; no statistical significant difference in mean MPV or mPAP with increased number of exacerbation per year, as shown in Figures 6 and 7. Also, when exacerbation frequency was taken into consideration in the logistic regression model, it did not appear as a significant independent predictor of the final outcome assessed; $\mathrm{PH}$. This may be explained by returning of inflammatory parameters that were consistent with an acute exacerbation to baseline values. ${ }^{30}$

The present work introduces a novel idea about using the MPV as an easy and reusable index to predict $\mathrm{PH}$, severe PH, and PASP in patients with COPD.
Our study limitation was the diagnosis of PH using Trans-thoracic Doppler echocardiography but in real practice the detection of PH was made mostly by echocardiography, and right heart catheterization (the gold standard diagnostic method for $\mathrm{PH}$ ) is an invasive and expensive procedure.

A meta-analysis had shown that; Trans-thoracic Doppler echocardiography had good sensitivity (83\%), reasonable specificity (72\%), and a correlation of 0.7 with invasively acquired measurements. ${ }^{49,50}$

D'Alto et $\mathrm{al}^{49}$ enrolled 161 patients referred for a suspicion of pulmonary hypertension, which was prospectively evaluated by a Doppler echocardiography performed by dedicated cardiologists within 1 hour of an indicated right heart catheterization. These authors used a Bland \& Altman analysis to define accuracy (which was good) and precision (which was acceptable, but for population studies) of Doppler echocardiography prediction of invasively measured pulmonary vascular pressures and flow. They concluded that there were no significant biases between echocardiographic and catheterization measurements of mean pulmonary artery pressure (mPAP) and other measured variables. Thus, the echocardiographic measurements compared to catheterization measurements taken as a gold standard were highly accurate.

\section{Conclusion}

MPV, a marker of platelet activity, was increased in COPD patients who developed $\mathrm{PH}$ and positively correlated with PH severity. If our data are to be confirmed, MPV may be taken in consideration in decision-making and management of COPD patients.

\section{Ethics approval and informed consent}

The research was approved from Bani-Swaif and Zagazig University Ethical Committees. Written informed consents were obtained from all participants. This study was conducted in accordance with the Declaration of Helsinki.

\section{Author contributions}

MFM, AA, and AA were responsible for study design, patient selection, and data collection. MSA and MG were responsible for performing Echocardiography for all selected patients. AMS was responsible for laboratory investigations. All authors contributed toward data analysis, drafting and revising the paper, gave final approval of the version to be published and agree to be accountable for all aspects of the work. 


\section{Disclosure}

The authors report no conflicts of interest in this work.

\section{References}

1. Burney PGJ, Patel J, Newson R, Minelli C, Naghavi M. Global and regional trends in COPD mortality, 1990-2010. Eur Respir J. 2015;45:1239-1247. doi:10.1183/09031936.00142414

2. Donaldson GC, Seemungal TAR, Patel IS, et al. Airway and systemic inflammation and decline in lung function in patients with COPD Chest. 2005;128:1995-2004. doi:10.1378/chest.128.4.1995

3. Galiè N, Humbert M, Vachiery JL, et al. Guidelines for the diagnosis and treatment of pulmonary hypertension: the task force for the diagnosis and treatment of pulmonary hypertension of the European Society of Cardiology (ESC) and the European Respiratory Society (ERS), endorsed by the International Society of Heart and Lung Transplantation (ISHLT). Eur Heart J. 2015;37:67-119.

4. Simonneau G, Robbins IM, Beghetti M, et al. Updated clinical classification of pulmonary hypertension. $\mathrm{J}$ Am Coll Cardiol. 2009;54:S43-S54. doi:10.1016/j.jacc.2009.04.012

5. Simonneau G, Montani D, Celermajer DS, et al. Haemodynamic definitions and updated clinical classification of pulmonary hypertension. Eur Respir J. 2019;53:1801913. doi:10.1183/ 13993003.01184-2018

6. Hoeper MM, Humbert M. The new haemodynamic definition of pulmonary hypertension: evidence prevails, finally! Eur Respir J. 2019;53:1900038. doi:10.1183/13993003.01184-2018

7. Gibbs JSR, Torbicki A. Proposed new pulmonary hypertension definition: is $4 \mathrm{~mm}(\mathrm{Hg})$ worth re-writing medical textbooks? Eur Respir J. 2019;53:1900197. doi:10.1183/13993003.011842018

8. Thabut G, Dauriat G, Stern JB, et al. Pulmonary hemodynamics in advanced COPD candidates for lung volume reduction surgery or lung transplantation. Chest. 2005;127:1531-1536. doi:10.1378/ chest.127.5.1531

9. Cuttica MJ, Kalhan R, Shlobin OA, et al. Categorization and impact of pulmonary hypertension in patients with advanced COPD. Respir Med. 2010;104:1877-1882. doi:10.1016/j.rmed.2010.05.009

10. Vernooy JH, Küçükaycan M, Jacobs JA, Chavannes NH, Buurman WA, Dentener MA. Local and systemic inflammation in patients with chronic obstructive pulmonary disease: soluble tumor necrosis factor receptors are increased in sputum. Am J Respir Crit Care Med. 2002;166:1218-1224. doi:10.1164/rccm.2202023

11. Maclay JD, McAllister DA, Mills NL, et al. Vascular dysfunction in chronic obstructive pulmonary disease. Am J Respir Crit Care Med. 2009;180:513-520. doi:10.1164/rccm.200903-0414OC

12. Alessandri C, Basili S, Violi F, et al. Hypercoagulability state in patients with chronic obstructive pulmonary disease. Thromb Haemost. 1994;72:343-346. doi:10.1055/s-0038-1648868

13. Wedzicha JA, Syndercombe-Court D, Tan KC. Increased platelet aggregate formation in patients with chronic airflow obstruction and hypoxaemia. Thorax. 1991;46:504-507.

14. Shen D, Wang Y. Effects of hypoxia on platelet activation in pilots. Aviat Space Environ Med. 1994;65:646-648.

15. Malerba M, Clini E, Malagola M, Avanzi GC. Platelet activation as a novel mechanism of atherothrombotic risk in chronic obstructive pulmonary disease. Expert Rev Hematol. 2013;6(4):475-483. doi:10.1586/ 17474086.2013.814835

16. Meyer T, Amaya M, Desai H, et al. Human platelets contain and release TWEAK. Platelets. 2010;21(7):571-574. doi:10.3109/09537104.2010.5 12403

17. Jasiewicz M, Moniuszko M, Pawlak D, et al. Activity of the kynurenine pathway and its interplay with immunity in patients with pulmonary arterial hypertension. Heart. 2016;102:230-237. doi:10.1136/ heartjnl-2015-308581
18. Jasiewicz M, Knapp M, Waszkiewicz E, et al. Enhanced IL-6 trans-signaling in pulmonary arterial hypertension and its potential role in disease-related systemic damage. Cytokine. 2015;76 (2):187-192. doi:10.1016/j.cyto.2015.06.018

19. Humbert M, Monti G, Brenot F, et al. Increased interleukin-1 and interleukin-6 serum concentrations in severe primary pulmonary hypertension. Am J Respir Crit Care Med. 1995;151(5):1628-1631. doi:10.1164/ajrccm.151.5.7735624

20. Jasiewicz M, Kowal K, Kowal-Bielecka O, et al. Serum levels of CD163 and TWEAK in patients with pulmonary arterial hypertension. Cytokine. 2014;66:40-45. doi:10.1016/j.cyto.2013.12.013

21. Bansal R, Gupta HL, Goel A, Yadav M. Association of increased platelet volume in patients of chronic obstructive pulmonary disease : clinical implications. JIACM. 2002;3(2):169-172.

22. Kazimierczyk R, Kamiński K. The role of platelets in the development and progression of pulmonary arterial hypertension. $A d v$ Med Sci. 2018;63(2):312-316. doi:10.1016/j.advms.2018.04.013

23. Merolla M, Nardi MA, Hu L, Rockman CB, Berger JS. Platelet size is an excellent surrogate for increased platelet activity. JACC. 2011;57(15):E1600. doi:10.1016/S0735-1097(11)61600-8

24. Bancroft AJ, Abel EW, Mclaren M, Belch J. Mean platelet volume is a useful parameter: a reproducible routine method using a modified Coulter thrombocytometer. Platelets. 2000;11(7):379-387.

25. Dastjerdi MS, Emami T, Najafian A, Amini M. Mean platelet volume measurement, EDTA or citrate? Hematology. 2006;11(5):317-319. doi:10.1080/10245330600954163

26. Koutsokera A, Kiropoulos TS, Nikoulis DJ, et al. Clinical, functional and biochemical changes during recovery from COPD exacerbations. Respir Med. 2009;103(6):919-926. doi:10.1016/j. rmed.2008.12.006

27. Kaushal M, Shah PS, Shah AD, Francis SA, Patel NV, Kothari KK. Chronic obstructive pulmonary disease and cardiac comorbidities: a cross-sectional study. Lung India. 2016;33(4):404-409. doi:10.4103/ 0970-2113.184874

28. Oswald-Mammosser M, Weitzenblum E, Quoix E, et al. Prognostic factors in COPD patients receiving long-term oxygen therapy: importance of pulmonary artery pressure. Chest. 1995;107(5):1193-1198. doi:10.1378/chest.107.5.1193

29. Maula F, Khan MN, Adil M, et al. Echocardiographic findings in chronic obstructive pulmonary disease (COPD) patients. Pak J Chest Med. 2015;19(1).

30. Ali ER. Role of mean platelet volume in patients with chronic obstructive pulmonary disease. Egypt J Bronchol. 2017;10:251-260. doi:10.4103/ $1687-8426.193635$

31. Chaouat A, Naeije R, Weitzenblum E. Pulmonary hypertension in COPD. Eur Respir J. 2008;32:1371-1385. doi:10.1183/ 09031936.00015608

32. Chatila WM, Thomashow BM, Minai OA, Criner GJ, Make BJ. Comorbidities in chronic obstructive pulmonary disease. Proc Am Thorac Soc. 2008;5:549-555. doi:10.1513/pats.200709-148ET

33. Gajanan K, Pophale H. Retrospective study of frequency of pulmonary hypertension in chronic obstructive pulmonary disease (COPD). Indian J Appl Res. 2014;4(12):400-401.

34. Naeije R. Pulmonary hypertension and Right heart failure in chronic obstructive pulmonary disease. Proc Am Thorac Soc. 2005;2:20-22. doi:10.1513/pats.200407-037MS

35. Scharf SM, Iqbal M, Keller C, Criner G, Lee S, Fessler HE. Hemodynamic characterization of patients with severe emphysema. Am J Respir Crit Care Med. 2002;166:314-322. doi:10.1164/rccm.2107027

36. Arcasoy SM, Christie JD, Ferrari VA, et al. Echocardiographic assessment of pulmonary hypertension in patients with advanced lung disease. Am J Respir Crit Care Med. 2003;167(5):735-740. doi: $10.1164 / \mathrm{rccm} .200210-11300 \mathrm{C}$

37. Gologanu D, Stanescu C, Ursica T, Balea MI, Ionita D, Bogdan MA. Prevalence and characteristics of pulmonary hypertension associated with COPD-A pilot study in patients referred to a pulmonary rehabilitation program clinic. Maedica. 2013;8(3):243-248. 
38. Ulasli SS, Ozyurek BA, Yilmaz EB, Ulubay G. Mean platelet volume as an inflammatory marker in acute exacerbation of chronic obstructive pulmonary disease. Pol Arch Med Wewn. 2012;122(6):284-290.

39. Rostango C, Prisco D, Boddi M, Poggesi L. Evidence for local platelet activation in pulmonary vessels in patients with pulmonary hypertension secondary to chronic obstructive pulmonary disease. Eur Respir J. 1991;4:147-151.

40. Nakstad B, Lyeberg T, Skjønsberg OH, Boye NP. Local activation of the coagulation and fibrinolysis system in lung disease. Thromb Res. 1990;57(6):827-838.

41. Segall M, Goetzman B. Hypoxic pulmonary hypertension: changes in platelet size and number. Amer J Perinatol. 1991;8(5):300-303. doi:10.1055/s-2007-999403

42. Lopes AAB, Maeda NY, Ebaid M, Chamone DAF. Aggregation of platelets in whole blood from children with pulmonary hypertension. Int J Cardiol. 1990;28(2):173-178. doi:10.1016/0167-5273(90) 90058-D

43. Can MM, Tanboga IH, Demircan HC, et al. Enhanced hemostatic indices in patients with pulmonary arterial hypertension: an observational study. Thromb Res. 2010;126(4):280-282. doi:10.1016/j. thromres.2010.06.020

44. Varol E, Uysal BA, Ozaydin M. Platelet indices in patients with pulmonary arterial hypertension. Clin Appl Thromb-Hem. 2011;17 (6):E171-E174. doi:10.1177/1076029610394438
45. Güvenc TS, Erer HB, Ilhan S, et al. Comparison of mean platelet volume values among different causes of pulmonary hypertension. Cardiol J. 2012;19(2):180-187.

46. Arslan D, Cimen D, Guvenc O, Kaya F, Sert A, Oran B. Platelet distribution width and mean platelet volume in children with pulmonary arterial hypertension secondary to congenital heart disease with left-to-right shunt: new indices of severity? Pediatr Cardiol. 2013;34:1013-1016. doi:10.1007/s00246-012-0600-5

47. Zhang M, Li Y, Zhang J, et al. Mean platelet volume is elevated in exacerbated and convalescent COPD patients. Clinica Chimica Acta. 2015;451:227-231. doi:10.1016/j.cca.2015.10.001

48. Celli BR, Thomas NE, Anderson JA, et al. Effect of pharmacotherapy on rate of decline of lung function in chronic obstructive pulmonary disease: results from the TORCH study. Am J Respir Crit Care Med. 2008;178(4):332-338. doi:10.1164/rccm.200712-18690C

49. D'Alto M, Romeo E, Argiento P, et al. Accuracy and precision of echocardiography versus right heart catheterization for the assessment of pulmonary hypertension. Int $J$ Cardiol. 2013;168 (4):4058-4062. doi:10.1016/j.ijcard.2013.07.005

50. Janda S, Shahidi N, Gin K, Swiston J. Diagnostic accuracy of echocardiography for pulmonary hypertension: a systematic review and meta-analysis. Heart. 2011;97(8):612-622. doi:10.1136/hrt.2010.212084

\section{Publish your work in this journal}

The International Journal of COPD is an international, peer-reviewed journal of therapeutics and pharmacology focusing on concise rapid reporting of clinical studies and reviews in COPD. Special focus is given to the pathophysiological processes underlying the disease, intervention programs, patient focused education, and self management protocols. This journal is indexed on PubMed Central, MedLine and CAS. The manuscript management system is completely online and includes a very quick and fair peer-review system, which is all easy to use. Visit http://www.dovepress.com/testimonials.php to read real quotes from published authors. 